\title{
KEANEKARAGAMAN IKAN (PISCES) DI DANAU SIPOGAS KABUPATEN ROKAN HULU PROVINSI RIAU
}

\section{DIVERSITY OF FISH (PISCES) IN SIPOGAS LAKE ROKAN HULU DISTRICT RIAU PROVINCE}

\author{
Puj Fauziah ${ }^{1 *}$, Arief Anthonius Purnama ${ }^{2}$, Rofiza Yolanda ${ }^{2}$, Ria Karno ${ }^{2}$ \\ ${ }^{1}$ Mahasiswa Program Studi Pendidikan Biologi, Fakultas Keguruan dan Ilmu Pendidikan, Universitas Pasir Pengaraian \\ 2Program Studi Pendidikan Biologi, Fakultas Keguruan dan Ilmu Pendidikan, Universitas Pasir Pengaraian \\ * Email: puijifauziah213@gmail.com
}

Naskah diterima 14 September 2016, Naskah disetujui 2 April 2017

\section{INTISARI}

Penelitian ini dilaksanakan pada bulan Mei sampai dengan Juli 2016 dengan tujuan mengetahui jenis-jenis ikan yang terdapat di Danau Sipogas Kabupaten Rokan Hulu Provinsi Riau. Dari hasil penelitian dengan metode survei pada 4 stasiun didapatkan sebanyak 3 ordo, 7 famili, 13 genus dan 14 spesies ikan dengan jumlah total keseluruhan adalah 353 individu. Spesies yang ditemukan adalah Anabas testudineus, Barbodes gonionotus, Belontia hasselti, Channa striata, Cyclocheilichthys apogon, Hampala macrolepidota, Helostoma temminckii, Kryptopterus limpok, Ompok eugeneiatus, Osteochilus hasseltii, Osteochilus mycrocephalus, Pristolepis grooti,Puntius lateristriga dan Rasborasp. Cyprinidae merupakan kelompok ikan yang paling banyak ditemukan dalam penelitian ini.

\section{Kata kunci: Keanekaragaman ikan, Danau Sipogas, Riau}

\begin{abstract}
This study has been conducted from May to July 2016 to inventory the species of fish from Sipogas lake, Rokan Hulu District, Riau Province. Result showed a total of 353 individuals of fish belonging to 3 order, 7 families, 13 genera and 14 species were recorded in this study, by using survey method at 4 stations, namely Anabas testudineus, Barbodes gonionotus, Belontia hasselti, Channa striata, Cyclocheilichthys apogon, Hampala macrolepidota, Helostoma temminckii, Kryptopterus limpok, Ompok eugeneiatus, Osteochilus hasseltii, Osteochilus mycrocephalus, Pristolepis grooti, Puntius lateristriga and Rasbora sp. Cyprinidae was the predominant fish in this study.
\end{abstract}

Keywords: Fish diversity, Sipogas lake, Riau

\section{PENDAHULUAN}

Ikan merupakan penghuni utama pada ekosistem akuatik (perairan) yang tersebar pada perairan tawar, seperti danau, sungai dan rawa serta perairan payau dan perairan laut (Pulungan, 2009; Allen dan Adrim, 2003; Augusta, 2015). Kottelat et al. (1993) menyatakan kebanyakan ikan air tawar tersebar di wilayah Asia bagian Tenggara pada kawasan tropis dengan jumlah kurang lebih sebanyak 105 suku (99\% diantaranya dapat ditemukan pada Indonesia bagian Barat).

Ikan memiliki peranan penting bagi ekosistem dan lingkungan, dimana dapat dijadikan sebagai bioindikator terhadap kualitas suatu badan perairan (Hendrata, 2004; Rahman dan Khairoh, 2012) dan juga berperan di dalam siklus rantai makanan (Kottelat et al., 1993). Muchlisin (2012) melaporkan spesies ikan Oreochromis mossambicus dan O. niloticus di perairan Aceh merupakan spesies omnivora yang mengakibatkan spesies ikan kecil punah. Jenis lain seperti ikan gabus Toraja juga tergolong predator/pemangsa di ekosistem perairan, bagi manusia dapat dimanfaatkan sebagai konsumsi, seperti ikan lele, ikan ikan gabus, ikan belanak, ikan kakap, ikan gurame, ikan mas, ikan betik, ikan mujair dan ikan nila (Rarung dan Pratasik, 2010). Ikan mas Carassius auratus dan Cyprinus carpio yang berasal dari Cina dan Jepang yang secara luas dikenal sebagai ikan hias maupun untuk tujuan budidaya (Kottelat et al., 1993).

Salah satu habitat yang menjadi distribusi ikan pada perairan tawar adalah danau yang merupakan badan perairan alami berukuran besar yang dikelilingi oleh daratan yang tidak bercampur dengan air laut, kecuali air sungai (Komite Nasional Pengelolaan Ekosistem Lahan Basah, 2004). Danau yang bisa dijumpai di Kabupaten Rokan Hulu adalah Danau Sipogas yang terletak di Desa Sialang Jaya, Kecamatan Rambah, Kabupaten Rokan Hulu. Danau ini berasal dari aliran air bukit Haorpit yang mengalir ke Kecamatan Rambah dan merupakan danau buatan yang dibuat oleh masyarakat sekitar. Danau ini telah dimanfaatkan oleh masyarakat sekitar sebagai tempat budidaya ikan (keramba), rekreasi dan alirannya juga dimanfaatkan sebagai irigasi. Aktivitas tersebut secara tidak langsung diduga telah mempengaruhi kualitas badan perairan pada danau Sipogas ini yang akan mempengaruhi organisme yang hidup didalamnya, salah satunya ikan. Akan tetapi sampai saat ini, informasi mengenai keberadaan dan 
spesies ikan yang terdapat pada danau ini belum pernah dilaporkan. Tujuan dari penelitian ini adalah untuk mengkoleksi dan mengetahui spesies ikan yang terdapat di Danau Sipogas, Kabupaten Rokan Hulu, Riau.

\section{MATERI DAN METODE}

Penelitian ini telah dilaksanakan di Danau Sipogas (o ${ }^{\circ} 49$ '19.96" N dan $100^{\circ} 16$ '50.44" E), yang terletak di Desa Sialang Jaya, Kecamatan Rambah, Kabupaten Rokan Hulu, Provinsi Riau pada bulan Mei sampai dengan Juli 2016. Penelitian ini dilaksanakan dengan menggunakan metode survei, dimana data atau sampel penelitian langsung dikoleksi dari lapangan, yang berasal pada empat stasiun. Penentuan stasiun pengamatan dalam penelitian ini didasarkan pada lokasi dan keterjangkauan akses dari danau. Analisis sampel dilakukan di Laboratorium Biologi, Program Studi Pendidikan Biologi, FKIP, Universitas Pasir Pengaraian.

Beberapa peralatan yang dipakai pada penelitian ini adalah jaring insang yang panjangnya $\pm 5 \mathrm{~m}$, lebar 1 m serta ukuran mata jaring 1 inchi dan 3/4 inchi, sipirai/bubu, tangguk/serok, pancing, rawai, jala, pancang, kantong plastik ukuran $5 \mathrm{~kg}$, sarung tangan, kertas label, botol sampel, kamera digital, pinset, alat tulis, rol (penggaris) dengan ketelitian $0,1 \mathrm{~cm}$, baskom, bak bedah, sampan dan GPS. Sedangkan bahan yang dipakai adalah alkohol 70\%, alkohol 90\% dan umpan (cacing, katak, dedak dan buah kelapa sawit). Sampel ikan didapat di lokasi langsung dimasukkan ke dalam wadah kemudian

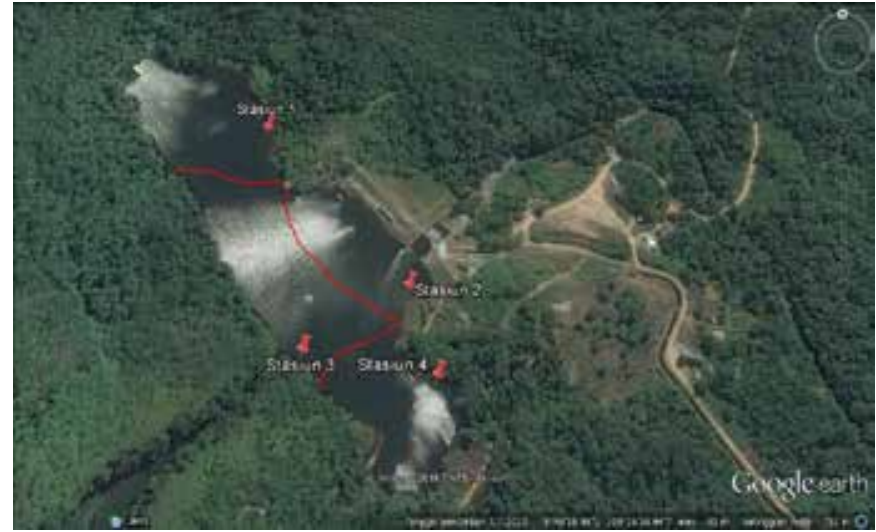

Gambar 1. Lokasi penelitian di Danau Sipogas, Kabupaten Rokan Hulu, Provinsi Riau

diawetkan menggunakan larutan alkohol 70\% atau alkohol 90\% serta diberikan label untuk keperluan analisis laboratorium. Penentuan spesies ikan diidentifikasi berdasarkan karakteristik morfologi dengan mengacu kepada Kottelat et al. (1993).

\section{HASIL}

Jumlah total ikan yang tertangkap selama penelitian di Danau Sipogas yakni sebanyak 353 individu yang terdiri atas 3 ordo, 7 famili, 13 genus dan 14 spesies. Adapun spesies yang didapatkan yaitu Anabas testudineus, Barbodes gonionotus, Belontia hasselti, Channa striata, Cyclocheilichthys apogon, Hampala macrolepidota,

Tabel 1. Data Spesies dan Jumlah Ikan yang Tertangkap dari Danau Sipogas Kabupaten Rokan Hulu.

\begin{tabular}{|c|c|c|c|c|c|c|}
\hline \multirow{2}{*}{ Ordo/Famili/Spesies } & \multirow{2}{*}{ Nama Lokal } & \multicolumn{4}{|c|}{ Stasiun } & \multirow{2}{*}{ Total } \\
\hline & & 1 & 2 & 3 & 4 & \\
\hline \multicolumn{7}{|l|}{ Cypriniformes } \\
\hline \multicolumn{7}{|l|}{ Cyprinidae } \\
\hline Barbodes gonionotus(Bleeker, 1850) & Lamasai & 11 & 97 & 7 & 36 & 151 \\
\hline Cyclocheilichthys apogon (Valencinnes, 1842) & Subahan & o & $\mathrm{O}$ & $\mathrm{O}$ & 5 & 5 \\
\hline Hampala macrolepidota(Kuhl dan Vanhasselt, 1823) & Barau & 5 & 21 & 11 & 9 & 46 \\
\hline Osteochilus hasseltii(Valencinnes, 1842) & Paweh & o & o & o & 3 & 3 \\
\hline Osteochilus mycrocephalus(Valencinnes, 1840) & Sengkaik & $\mathrm{o}$ & $\mathrm{O}$ & 6 & 3 & 9 \\
\hline Puntius lateristriga(Valenciennes, 1842) & Tunggulubuk & 18 & 11 & 24 & 17 & 70 \\
\hline Rasbora sp. & Bada & 0 & 8 & 3 & 11 & 22 \\
\hline \multicolumn{7}{|l|}{ Perciformes } \\
\hline \multicolumn{7}{|l|}{ Anabantidae } \\
\hline Anabas testudineus(Bloch, 1792) & Betik & $\mathrm{O}$ & $\mathrm{O}$ & $\mathrm{O}$ & 1 & 1 \\
\hline \multicolumn{7}{|l|}{ Channidae } \\
\hline Channa striata(Bloch, 1793) & Gabus & 3 & 5 & 2 & 2 & 12 \\
\hline \multicolumn{7}{|l|}{ Helostomatidae } \\
\hline Helostoma temminckii Cuvier 1829 & Bulan-bulan & o & o & 2 & 4 & 6 \\
\hline \multicolumn{7}{|l|}{ Osphronemidae } \\
\hline Belontia hasselti(Cuvier dan Valenciennes, 1831) & Keper & o & o & 2 & 3 & 5 \\
\hline \multicolumn{7}{|l|}{ Pristolipididae } \\
\hline Pristolepis grooti(Bleeker, 1852) & Katung & 4 & 9 & 3 & $\mathrm{O}$ & 16 \\
\hline \multicolumn{7}{|l|}{ Siluriformes } \\
\hline \multicolumn{7}{|l|}{ Siluridae } \\
\hline Kryptopterus limpok(Bleeker, 1852) & Selais & o & o & 1 & 2 & 3 \\
\hline Ompok eugeneiatus(Vaillant, 1893) & Selais & o & o & 2 & 2 & 4 \\
\hline Total & & 41 & $\mathbf{1 5 1}$ & 63 & 98 & 353 \\
\hline
\end{tabular}




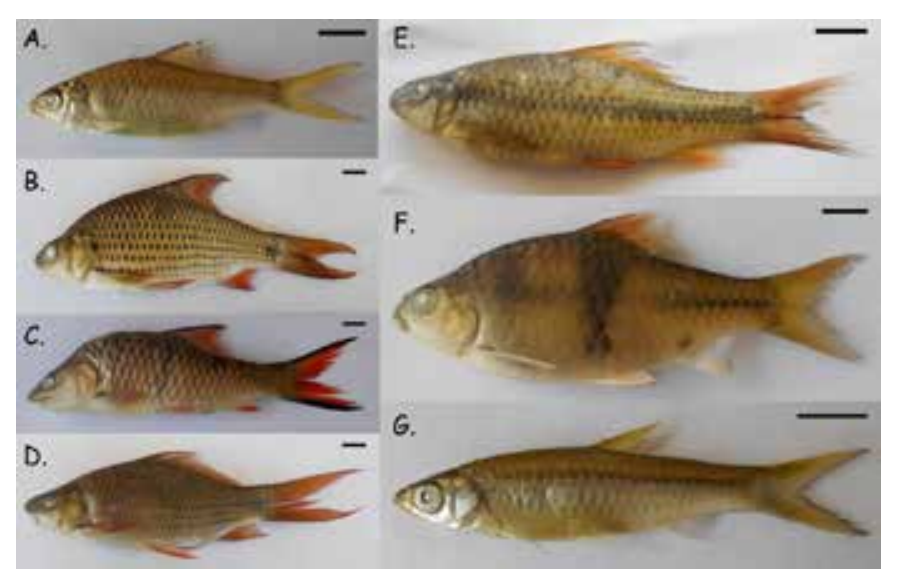

Gambar 2. Dokumentasi spesies ikan dari ordo Cypriniformes yang didapatkan di lokasi penelitian. (A). Barbodes gonionotus, (B).Cyclocheilichthys apogon, (C). Hampala macrolepidota, (D).Osteochilus hasseltii, (E).Osteochilus mycrocephalus, (F).Puntius lateristriga, (G). Rasborasp. Skala bar $=1 \mathrm{~cm}$.

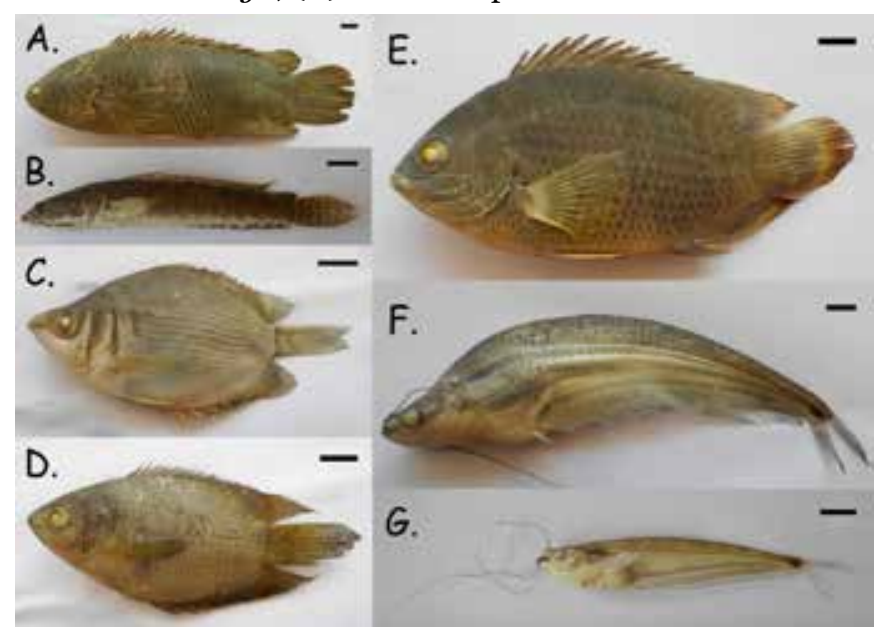

Gambar 3. Dokumentasi spesies ikan dari famili Perciformes dan Siluriformes yang didapatkan di lokasi penelitian. (A). Anabas testudineus, (B).Channa striata, (C).Helostoma temminckii, (D).Belontia hasselti, (E).Pristolepis grooti (F).Kryptopterus limpok, (F).Ompok eugeneiatus. Skala bar $=1 \mathrm{~cm}$.

Helostoma temminckii, Kryptopterus limpok, Ompok eugeneiatus, Osteochilus hasseltii, Osteochilus mycrocephalus, Pristolepis grooti, Puntius lateristriga dan Rasbora sp. Hasil pengamatan menunjukkan terdapat 3 ordo diantaranya adalah ordo Cypriniformes yang terdiri dari famili Cyprinidae dengan spesiesnya Barbodes gonionotus, Cyclocheilichthys apogon, Hampala macrolepidota, Osteochilus hasseltii, Osteochilus mycrocephalus, Puntius lateristriga dan Rasbora sp. Ordo Perciformes yang terdiri dari 5 famili yaitu Channidae dengan spesiesnya Channa striata, famili Pristolipididae dengan spesiesnya Pristolepis grooti, famili Anabantidae dengan spesiesnya Anabas testudineus, famili Osphronemidae dengan spesiesnya Belontia hasselti, famili Helostomatidae dengan spesiesnya Helostoma temminckii. Ordo Siluriformes yang terdiri dari famili Siluridae dengan spesies Kryptopterus limpok dan Ompok eugeneiatus (Tabel 1; Gambar 2 dan 3).
Dari hasil pengamatan pada masing-masing stasiun penelitian dari Tabel 1 di atas, jumlah ikan yang didapatkan berturut-turut adalah sebagai berikut pada stasiun 1 sebanyak 41 individu, stasiun 2 sebanyak 151 individu, stasiun 3 sebanyak 63 individu dan stasiun 4 sebanyak 98 individu. Jumlah ikan yang paling banyak ditemukan terdapat pada stasiun 2 dan diikuti stasiun 4, hal ini disebabkan kondisi lingkungan perairan yang dangkal dan dekat dengan laju aliran air/air mengalir. Sedangkan pada stasiun 1 dan 3 jumlah individu yang didapatkan tidak terlalu banyak, hal ini karena kondisi lingkungan perairan dalam dan jauh dari aliran air mengalir.

\section{PEMBAHASAN}

Spesies dengan jumlah yang paling banyak ditemukan secara berturut-turut adalah Barbodes gonionotus (151 individu), diikuti Puntius lateristriga (70 individu), Hampala macrolepidota (46 individu), Rasbora sp. (22 individu), Pristolepis grooti (16 individu), Channidae (12 individu), Osteochilus mycrocephalus (9 individu), Helostoma temminkii (6 individu), Cyclocheilichthys apogon (5 individu) dan Osteochilus hasseltii (3 individu). Secara keseluruhan jumlah ikan yang paling banyak tertangkap berasal dari famili Cyprinidae, karena ikan dari kelompok ini memiliki penyebaran dan jumlah yang sangat banyak. Hedianto et al. (2013) melaporkan ikan Barbodes gonionotus merupakan salah satu spesies ikan yang umum ditemukan pada perairan tawar. Kottelat et al. (1993) menyatakan Cypinidae memang telah dikenal sebagai penghuni utama yang paling besar populasinya untuk beberapa sungai di Sumatera disamping Bagridae, Clariidae dan Pangasidae. Cyprinidaemerupakan suku yang sangat besar dan terdapat hampir di setiap tempat kecuali di daerah Australia, Madagaskar, Selandia Baru, dan Amerika Selatan (walaupun di beberapa tempat tersebut pernah dilakukan introduksi). Nelson (2006) mengidentifikasi beberapa ordo ikan terdiri dari 6 famili, 321 genera dan 3.268 species. Di antara keenam famili tersebut, yang paling banyak ditemukan berasal dari famili Cyprinidae. Rainboth (1991) juga menyatakan di wilayah Asia Tenggara famili Cyprinidae memiliki keanekaragaman spesies yang sangat banyak. Begitu juga Le've^que et al. (2008) menyatakan Cyprinidae merupakan kelompok ikan air tawar yang paling banyak secara global.

Beberapa penelitian mengenai keanekaragaman ikan tawar yang terdapat di perairan danau juga melaporkan bahwa ikan dari famili Cyprinidae merupakan kelompok yang paling banyak/dominan menghuni perairan danau, seperti yang dilaporkan oleh Buchar (1998) dari Danau Sabuah, Kalimantan Tengah; Nurdawati et al. (2006) dari Danau Teluk Mahligai dan Danau Napal Tapak Sisik, Jambi; Siagian (2009) dari Danau Toba Balige Sumatera Utara; Hestimaya (2010) dari Danau Lido, Bogor, Jawa Barat; Roesma (2013) dari Danau Maninjau Sumatera Barat; Amar et al. (2014) dari Danau Cala Kabupaten 
Musi Banyuasin Sumatera Selatan; Augusta (2015) dari Danau Hanjalutung Kalimantan Tengah.

Kemudian salah satu faktor yang mempengaruhi banyak ataupun sedikit jumlah ikan pada perairan air tawar adalah laju aliran air. Badan perairan yang mengalir sangat baik pertumbuhan dan pengembangan fisik ikan (Parlaungan, 2016). Di samping pembawa bahan terlarut, sirkulasi air juga membawa zat tersuspensi serta kotoran, yang akan berdampak pada kadar oksigen dalam air yang dibutuhkan oleh ikan (Affan, 2012; Widyastusi, 2016).

\section{SIMPULAN}

Total ikan yang ditemukan selama penelitian ini dilaksanakan berjumlah sebanyak 353 individu yang terdiri dari 3 ordo, 7 famili, 13 genus dan 14 spesies. Spesies yang ditemukan adalah Anabas testudineus, Barbodes gonionotus, Belontia hasselti, Channa striata, Cyclocheilichthys apogon, Hampala macrolepidota, Helostoma temminckii, Kryptopterus limpok, Ompok eugeneiatus, Osteochilus hasseltii, Osteochilus mycrocephalus, Pristolepis grooti, Puntius lateristriga dan Rasbora sp. Famili Cyprinidae merupakan kelompok ikan yang paling banyak ditemukan dalam penelitian ini.

\section{KEPUSTAKAAN}

Affan, J.M. 2012. Identifikasi Lokasi untuk Pengembangan Budidaya Keramba Jaring Apung (KJA) Berdasarkan Faktor Lingkungan dan Kualitas Air di Perairan Pantai Timur Bangka Tengah. Depik, 1(1): 78-85.

Allen, G.R. and M. Adrim. 2003. Coral Reef Fishes of Indonesia. Zoological Studies, 42(1): 1-72.

Amar, J. A., M. M. Kamal dan Sulistiono. 2014. Keragaman Ikan di Danau Cala, Kabupaten Musi Banyuasin, Sumatera Selatan. Depik, 3(3): 216-220.

Augusta,T.S. 2015. Inventarisasi Ikan dan Kondisi Habitat di Danau Hanjalutung, Kalimantan Tengah. Jurnal Ilmu Hewani Tropika, 4(2): 45-48.

Buchar, T. 1998. Bioekologi Komunitas Ikan di Danau Sabuah, Kabupaten Kapuas, Propinsi Kalimantan Tengah. Tesis. Program Pascasarjana, Institut Pertanian Bogor. Bogor.

Hedianto, D.A., K. Purnomo dan A. Warsa. 2013. Interaksi Pemanfaatan Alami oleh Komunitas Ikan di Waduk Penjalin, Jawa Tengah. Bawal, 5(1): 33-40.

Hendrata, S. 2004. Pemanfaatan Ikan Nila (Oreochromis niloticus) sebagai Bioindikator untuk Menilai Efektifitas Kinerja Ipal Rumah Sakit Pupuk KALTIM, Bontang. Tesis.Program Magister Ilmu Lingkungan, Universitas Diponegoro. Semarang.

Hestimaya, E. 2010. Studi Iktiofauna di Danau Lido, Kabupaten Bogor, Jawa Barat. Skripsi.Departemen Manajemen Sumberdaya Perairan, Fakultas Perikanan dan Ilmu Kelautan, Institut Pertanian Bogor. Bogor.

Komite Nasional Pengelolaan Ekosistem Lahan Basah.
2004. Strategi Nasional dan Rencana Aksi Pengelolaan Lahan Basah Indonesia. Wetland InternationalIP: Bogor.

Kottelat, M., J.A.Whitten, S. N. Kartikasari danS. Wirdjoatmojo. 1993. Freshwater Fishes of Western Indonesia and Sulawesi. Periplus Edition. (HK) in Collaboration with the Environmental Republik Indonesia: Jakarta.

Le've^que, E., T. Oberdorff, D. Paugy, M. L. J. Stiassny and P. A. Tedesco. 2008. Global Diversity of Fish (Pisces) in Freshwater. Hydrobiologia, 595: 545-567.

Muchlisin, Z.A. 2012. First Report on Introduced Freshwater Fishes in the Water of Aceh, Indonesia. Arch. Pol. Fish, 20: 129-135.

Nelson, J.S. 2006. Fishes of the World. Fourth edition. John Wiley and Sons, Inc.: Canada.

Nurdawati, S., A. S. Nastiti, H. Satria dan A. Suryandari. 2006. Komposisi Jenis dan Habitat Ikan di Danau Mahligai dan Danau Napal Sisik, Propinsi Jambi. Prosiding Seminar Nasional Ikan IV, Jatiluhur 29-30 Agustus 2006.hal. 63-76.

Parlaungan, Y. 2016. Faktor Penentu Budidaya Ikan Air Tawar. [cited: 2016 August 30]. Available at: http:// bakorluh.riau.go.id/yansen_parlaungan/images/ stories/perikanan/faktentuikantwr.pdf.

Pulungan, C.P. 2009. Fauna Ikan dari Sungai Tenayan, Anak Sungai Siak dan Rawa Disekitarnya Riau. Berkala Perikanan Terubuk, 37(2): 78-90.

Rahman, A. dan L.W. Khairoh. 2012. Penentuan Tingkat Pencemaran Sungai Desa Awang Bangkal Berdasarkan Nutrition Value Oeficient dengan Menggunakan Ikan Nila (Oreochromis niloticus Linn.) sebagai Bioindikator. Jurnal Ekosains, IV(1): 1-10.

Rainboth, W.J. 1991.Cyprinids of South East Asia. I.J.Winfield, J.S. Nelson (Eds), Cyprinid Fishes Systematics, Biology and Exploitation.Chapman and Hall: London.

Rarung, L.K. dan S. Pratasik. 2010. Potensi Jenis-Jenis Ikan Air Tawar Konsumsi Masyarakat Aliran Sungai Digoel, Kabupaten Boven Digoel, Papua dan Beberapa Langkah Pengelolaanya. Jurnal Perikanan dan Kelautan, VI(1): 41-45.

Roesma, D. I. 2013. Evaluasi Keanekaragaman Spesies Ikan Danau Maninjau. Prosiding Seminar Semirata FMIPA BKS Barat-FMIPA Universitas Lampung, Lampung 10-12 Mei 2013. hal. 197-204.

Siagian, C. 2009. Keanekaragaman dan Kelimpahan Ikan serta Keterkaitannya dengan Kualitas Perairan di Danau Toba Balige, Sumatera Utara. Tesis.Sekolah Pascasarjana, Universitas Sumatera Utara. Medan.

Widyastuti, E. 2016. Budidaya Ikan dalam Keramba di Perairan Mengalir. [cited: 2016 August 30]. Available at: http://bio.unsoed.ac.id/sites/default/files/ Budidaya\%20Ikan\%2odalam\%20Keramba\%20 di\%2oPerairan\%2oMengalir-.pdf. 